Surgery for

Congenital

Heart Disease

\title{
The Ross procedure is the procedure of choice for congenital aortic valve disease
}

Zohair Al-Halees, MD, FRCSC

Frans Pieters, MD

Fatima Oadoura, MD

Maie Shahid, MD

Mohammed Al-Amri, MD

Fadel Al-Fadley, MD
From the Department of Cardiovascular Diseases, King Faisal Specialist Hospital \& Research Centre, Riyadh, Saudi Arabia.

Read at the Eighty-first Annual Meeting of The American Association for Thoracic Surgery, San Diego, Calif, May 6-9, 2001.

Received for publication May 18, 2001; revisions requested June 14, 2001; revisions received July 27, 2001; accepted for publication Aug 7, 2001.

Address for reprints: Zohair Al-Halees, MD, Chairman, Department of Cardiovascular Diseases, King Faisal Specialist Hospital \& Research Centre, PO Box 3354, Riyadh 11211, Saudi Arabia (E-mail: alhalees@ kfshrc.edu.sa)

J Thorac Cardiovasc Surg 2002;123:437-42

Copyright (C) 2002 by The American Association for Thoracic Surgery

$0022-5223 / 2002 \$ 35.00+0 \quad \mathbf{1 2 / 6 / 1 1 9 7 0 5}$

doi:10.1067/mtc.2002.119705
Objectives: The Ross procedure has emerged as an attractive option for aortic valve replacement in children and young adults. Our objective was to review our experience with the Ross procedure in young patients with congenital aortic valve disease. We also sought for evidence of growth in the autograft.

Methods: From January 1990 to July 2000, 260 patients underwent the Ross procedure for various aortic valve diseases. There were 136 patients less than 18 years of age. Fifty-three (38\%) of these patients had congenital aortic valve disease. Ages ranged from 3 months to 18 years (mean, $8 \pm 5$ years; median, 9 years). Ten patients were less than 2 years of age. Pure aortic stenosis was present in 18 patients, mixed stenosis and regurgitation in 32 , and pure aortic regurgitation in 3 . The aortic valve was bicuspid in 29 patients. Twenty-nine patients had previous procedures, mostly balloon dilation of the aortic valve $(n=8)$ or surgical aortic valvotomy $(n=12)$.

Results: In all patients immediate results demonstrated a normally functioning neoaortic valve with not more than trivial aortic valve regurgitation. In the patients with stenosis, all levels of obstruction were relieved, and the gradient across the left ventricular outflow tract was completely abolished. Hospital mortality was $3(5.6 \%)$ of 53 (overall Ross mortality was 34 of 260 [1.5\%]). The patients were followed up for a mean of 4 years and up to 10 years. One patient died late of a noncardiac cause. Actuarial survival at 10 years was $94 \% \pm 2 \%$, and freedom from all events was $93 \% \pm 5 \%$. Only 1 patient needed autograft replacement for endocarditis. Intervention related to right ventricle-pulmonary artery conduit was required in 3 patients: balloon dilatation in 2, and reoperation in 1. At last follow-up, all patients but one were classified as being in New York Heart Association functional class I or II with normal or near-normal autograft valve function. Serial measurement of the left ventricular outflow tract and aortic root showed that as patients grew, the size of the outflow tract increased. When indexed to body surface area, this increase correlated with the patients' expected somatic growth.

Conclusions: The Ross procedure for congenital aortic valve disease in children and young adults offers excellent hemodynamics, with the added advantage of real potential for growth. It should be considered the treatment of choice in this age group.

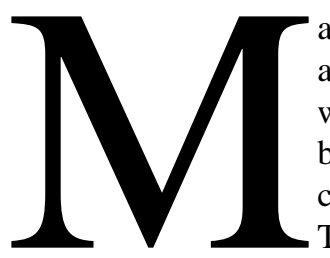

anagement of aortic valve disease in children and young adults is somewhat controversial. Aortic valve replacement, whether with a mechanical prosthesis or a bioprosthesis, can be unsatisfactory. Mechanical valves require long-term anticoagulation, with its known potential for complications. There is always a threat of thromboembolism and bleeding. ${ }^{1}$ 
TABLE 1. Interventions before the Ross procedure

\begin{tabular}{lc}
\hline Procedure & No. of patients \\
\hline AV balloon dilation & 8 \\
AV surgical valvotomy & 12 \\
\pm AV repair + coarctation & 1 \\
+ VSD + LVOTO + coarctation & 1 \\
Resection of SAM & 5 \\
Other congenital disorder & 4 \\
PDA & 1 \\
VSD & 1 \\
VSD + coarctation & 1 \\
VSD + aortic interruption & 1 \\
\hline
\end{tabular}

$A V$, Aortic valve; $S A M$, subaortic membrane; $V S D$, ventricular septal defect; LVOTO, LVOT obstruction; PDA, patent ductus arteriosus.

Young adults' participation in some sports activity might have to be restricted. Management of anticoagulation during pregnancy can be a real problem. There is always the risk of valve thrombosis, ${ }^{2,3}$ and warfarin is known to have teratogenic effects on the fetus. ${ }^{4}$ Bioprosthetic valves have a very high rate of early calcification and failure in this age group. ${ }^{5}$ Allografts also have a high failure rate when implanted in the very young. ${ }^{6}$ Because of continued growth of these patients, there is always a need for multiple valve replacements. Aortic valve replacement with the autologous pulmonary valve (the Ross procedure) eliminates almost all these problems. There is no risk of thromboembolism, and there is a definite potential for growth. ${ }^{7}$ The autologous valve allows a growing child to have a normal lifestyle. There is a more than $80 \%$ likelihood of freedom from reoperation at 10 years and a $97 \%$ probability of freedom from any sort of right ventricular outflow tract (RVOT) complications or reoperation at 20 years. ${ }^{8}$

Because of all of this, we adopted the policy of using the pulmonary autograft for aortic valve replacement in the very young whenever feasible.

\section{Methods}

From January 1990 to July 2000, 260 patients had aortic valve replacement with the autologous pulmonary valve (the Ross procedure). There were 136 patients less than 18 years of age. Fiftythree (38\%) of these had congenital aortic valve disease, and these patients constitute the study group. Ages ranged from 3 months to 18 years, with a mean of $8 \pm 5$ years (median, 9 years). Ten patients were less than 2 years of age. Pure aortic stenosis was present in 18 patients, 32 had both aortic stenosis and regurgitation, and 3 had pure aortic regurgitation. There were $29(55 \%)$ male patients and 24 (45\%) female patients. Twenty-nine patients had previous procedures (Table 1). The aortic valve was bicuspid in 29 patients. Forty-one patients were classified as being in New York Heart Association functional class I or II, 8 patients were in class III, and 4 patients were in class IV. Fifty-one patients were in
TABLE 2. Status of the neoaortic valve function after the Ross procedure in the 49 survivors

\begin{tabular}{lrr}
\hline & AR & AS \\
\hline None & 18 & 49 \\
Trivial & 12 & 0 \\
Mild & 16 & 0 \\
Moderate & 3 & 0 \\
Severe & 0 & 0
\end{tabular}

None of the patients has aortic stenosis $(A S)$, whereas some aortic regurgitation $(A R)$ is noted.

sinus rhythm, 1 was in atrial fibrillation, and 1 had a pacemaker from a previous operation.

The autograft was implanted as a full root with coronary transfer using conventional cardiopulmonary bypass with double venous cannulation. Temperature was kept between $28^{\circ} \mathrm{C}$ and $32^{\circ} \mathrm{C}$. Cardioplegic solution was delivered in both an antegrade and retrograde fashion. The neoaortic anulus was not reinforced in these patients, so as not to limit growth. In patients with left ventricular outflow tract (LVOT) obstruction, a modified Ross-Konno technique was used. Part of the septum was actually cored out to completely open up the LVOT without creating a ventricular septal defect. In those patients the fibrous anulus of the aortic valve was often divided, and the cut was partially taken down to the septum. In all patients this resulted in complete relief of the obstruction, and the often larger pulmonary autograft could be accommodated nicely in the aortic position. In none of the patients was the pulmonary autograft significantly smaller than the aortic root. However, on the basis of our overall Ross experience, up to a 3- to 4-mm discrepancy in size can be accommodated. The RVOT was reconstructed with either an aortic or pulmonary homograft. These were either cryopreserved or fresh-antibiotic preserved. In 1 patient, however, no homografts were available, and a valved tube constructed of glutaraldehyde-treated autologous pericardium was used. The median diameter was $22 \mathrm{~mm}$ (range, 19-25 mm). Patients less than 14 years of age were given cyclosporine A (INN: ciclosporin) orally at a dosage of $1 \mathrm{mg} \cdot \mathrm{kg}^{-1} \cdot \mathrm{d}^{-1}$.

The immediate postoperative result was assessed in all patients in the operating room by means of transesophageal echocardiography. Patients were evaluated clinically and by means of detailed echocardiography 6 weeks after the operation, at 6 months, and yearly thereafter.

Patient survival analysis and actuarial estimates of freedom from postoperative events were accomplished by means of the Cox life table method.

\section{Results}

The mean cardiopulmonary bypass time was $109 \pm 36$ minutes (range, 52-243 minutes), and the mean aortic crossclamp time was $79.5 \pm 24$ minutes (range, $45-164$ minutes). Immediate echocardiographic evaluation in the operating room demonstrated good results in all patients with not more than trivial aortic valve regurgitation. All levels of 


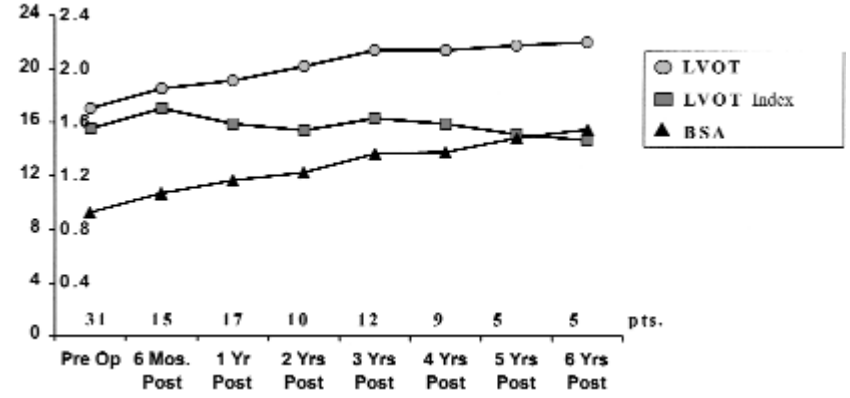

Figure 1. LVOT size after Ross procedure for congenital aortic valve disease. BSA, Body surface area.

obstruction were completely relieved, with the gradients being completely abolished. There were $3(5.6 \%)$ in-hospital deaths. All 3 patients had severe aortic valve stenosis and LVOT obstruction associated with severe left ventricular hypertrophy. Their ages were 2,9 , and 13 years. Their deaths were related to myocardial dysfunction, probably caused by inadequate myocardial preservation, ischemia, or both. There was no significant morbidity, with only 1 patient needing reoperation for bleeding. Another patient needed implantation of a permanent pacemaker.

The patients were followed up for up to 10 years, with a mean follow-up of 4 years. One patient died late of a noncardiac cause. Actuarial survival at 10 years was $94 \% \pm 2 \%$, and freedom from all events was $93 \% \pm 5 \%$. One patient needed reoperation for autograft failure related to endocarditis 1 year after undergoing the Ross procedure. Intervention related to right ventricle-pulmonary artery conduit was required in 3 patients: balloon dilation with moderate success in 2 patients and reoperation in 1 patient. The reoperation was for the patient who had the valved glutaraldehyde-treated autologous pericardial conduit to reconstruct the RVOT. It was replaced with a pulmonary homograft. The aortic valve was functioning normally.

At last follow-up, all patients but 1 were classified in New York Heart Association functional class I or II with normal or near-normal autograft function (Table 2). One of the patients with moderate aortic regurgitation also had impaired left ventricular function, requiring medical therapy with angiotensin-converting enzyme inhibitors, digoxin, and diuretics. All the other patients had preserved left ventricular function.

The homografts in the pulmonary position demonstrated gradients in 14 patients. In 9 of these patients, the gradients were of less than $35 \mathrm{~mm} \mathrm{Hg}$ and were well tolerated, with no associated right ventricular dilation or dysfunction. Five (9\%) patients had gradients of greater than $50 \mathrm{~mm} \mathrm{Hg}$. Three of them needed intervention. Most homografts also

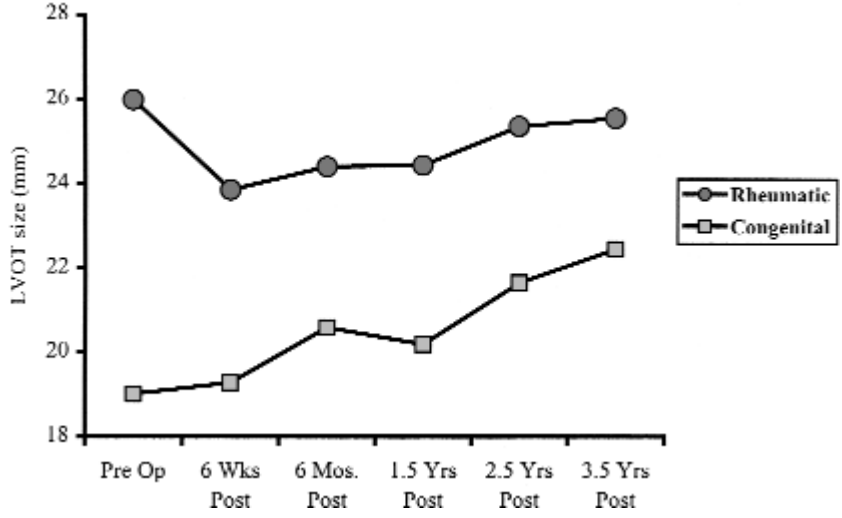

Figure 2. LVOT size comparing rheumatic versus congenital aortic valve disease after Ross procedure.

TABLE 3. Degree of pulmonary valve regurgitation after homograft replacement after the Ross procedure in the $\mathbf{4 9}$ survivors

\begin{tabular}{lc}
\hline Pulmonary regurgitation & No. of patients \\
\hline None/trivial & 20 \\
Mild & 16 \\
Moderate & 9 \\
Severe & 4 \\
\hline
\end{tabular}

had some degree of pulmonary regurgitation, which in some existed without stenosis (Table 3).

Serial echocardiographic measurements of the LVOT and aortic root diameter demonstrated that as the patients grew, the size of the LVOT increased. When indexed to body surface area, the increase correlated with the patients' expected somatic growth (Figure 1).

\section{Discussion}

The surgical management of aortic valve disease in the young has been confined to prosthetic replacement in most centers. Mechanical valves need lifelong anticoagulation, with its known risk of thromboembolism and bleeding. Noncompliance with medical treatment and pregnancy further accentuate this problem. The use of bioprostheses is discouraged because of early failure and degeneration. Allografts, although with relatively longer durability than stented bioprostheses, are still not advisable in children. Their limited availability also restricts widespread use. Aortic valve repair techniques have been applied but to a limited extent. Currently, there is a growing interest in these techniques, but they are associated with some failures and the need for reoperation. ${ }^{9}$ 
Aortic valve replacement with the autologous pulmonary valve offers the advantages of a viable, ${ }^{10}$ nonstented tissue valve with growth potential. ${ }^{7,11}$ It does not require anticoagulation, and with its proven long-term outcome, ${ }^{11,12}$ the indications for its use are becoming broader, especially in young patients. At the end of 1999, close to 4000 patients have been enrolled into the international Ross registry (personal communication, Ross Procedure International Registry, St Patrick Hospital, Missoula, Mont). Faced with a predominantly young and rheumatic patient population in whom anticoagulation control is extremely difficult, we adopted the procedure in our institution in January 1990. Since then and until the end of July 2000, 260 patients underwent the Ross procedure, with an overall mortality of $1.5 \%$. Seventy percent of our patients have rheumatic disease. Initially, there was a significant need for reoperation in this group of patients because of progression of aortic regurgitation in the autograft. Rheumatic valvulitis was documented in some explanted autograft valves at reoperation, indicating that the transplanted pulmonary valve can be sensitive to rheumatic fever. Our concern about the use of the Ross operation in patients with rheumatic disease was reported. ${ }^{13,14} \mathrm{We}$ also found that associated concomitant severe mitral valve regurgitation was a strong predictor of autograft failure. The presence of dilated aortic root preoperatively was another risk factor predictive of failure. We now do not offer the Ross procedure for rheumatic aortic valve regurgitation if the root is more than $28 \mathrm{~mm}$ in diameter.

In our effort to reduce the reoperation rate, we found that patients with predominant aortic stenosis had a much lesser incidence of reoperation than those with pure aortic regurgitation, who tend to have larger aortic roots. We therefore decided to look at our subgroup of patients with congenital aortic valve disease and determine whether they differed from those with a rheumatic cause.

Patients with congenital aortic valve disease were younger (mean age, $8 \pm 5$ years vs $18 \pm 9$ years in those with rheumatic disease). They had more stenotic lesions and smaller LVOTs (Figure 2).

As our experience indicates, the pulmonary autograft replacement of the aortic valve seems to be the ideal solution in children and young adults. The operation can be accomplished with a relatively low operative risk. The root replacement technique can correct almost all pathologic lesions associated with the aortic valve and the LVOT. A severely obstructed LVOT can be dealt with adequately by means of modified Ross-Konno procedure in which the LVOT is enlarged in the area of the septum without actually creating a ventricular septal defect, and the aortic valve is replaced with the pulmonary autograft. However, it is the opinion of many others that if the patient's own aortic valve is of acceptable quality, then one should attempt to do a repair, preserving the valve whenever possible. ${ }^{15}$
Late valve function has been excellent, and the only primary autograft failure was related to endocarditis. All other patients have normal or near-normal autograft valve function (Table 2), with no evidence of deterioration up to 10 years of follow-up. The Ross operation appears to have a significant advantage in survival and quality of life in children requiring valve replacement not only as a first operation but also after a prior aortic valve procedure. ${ }^{16}$

Problems with the homograft used in reconstruction of the RVOT are not significant, although up to about $20 \%$ of patients tend to have gradients. In this series $9(16 \%)$ of 53 patients had gradients of less than $35 \mathrm{~mm} \mathrm{Hg}$. An additional 5 (9\%) patients had gradients of more than $50 \mathrm{~mm} \mathrm{Hg}$. Three of these patients required intervention: 2 balloon dilations and 1 operation. The balloon dilation resulted in only modest reduction in the gradients. Balloon dilation in such patients generally is not successful in relieving the gradients altogether because the gradients result from diffuse narrowing of the homograft involving the homograft valve anulus, the pulmonary artery, and also the distal suture line and often are associated with calcification and thickening in the valve leaflets. If, however, the stenosis was only caused by narrowing of the distal suture line, balloon dilation may be more successful. The diffuse nature of the narrowing is thought to represent a consequence of an immune-mediated response to the homograft. ${ }^{17,18}$ Because of this, we empirically give our young patients who receive homografts cyclosporine at $1 \mathrm{mg}$ $\cdot \mathrm{kg}^{-1} \cdot \mathrm{d}^{-1}$ orally. This dosage is quite small and will not cause any significant adverse effects and yet may slow down the rate of homograft degeneration. It is also worth mentioning that the risk for development of homograft stenosis is greatest during the first 1 to 3 years postoperatively. Subsequently, it appears that the gradients stabilize in most of the patients. Our policy therefore is to observe these patients unless there is evidence of right ventricular strain on the electrocardiogram or right ventricular dilation or dysfunction on echocardiography. If there is uncertainty, we evaluate the patient during exercise. If the exercise tolerance is affected, then intervention is indicated. With this, our reoperation rate on the right side for the whole Ross group is only $2 \%$. In this subgroup the only patient who needed reoperation on the right side had a valved conduit constructed of glutaraldehyde-treated autologous pericardium. One reason that homografts do well in RVOT reconstruction after the Ross procedure is the fact that the homograft is actually lying in its anatomic position with most favorable hemodynamics, unlike the situation with most right-sided reconstructions for congenital heart disease, where the homograft lies on top of the ventricle, making hemodynamics less than ideal. Additionally, patients undergoing the Ross procedure have a relatively normal pulmonary vascular bed compared with that of patients with congenital heart disease, who often have abnormalities in their distal pulmonary bed. 
One of the great advantages of the Ross operation is the real potential for growth. There is no doubt that serial measurements of the LVOT and aortic root demonstrate progressive increase in size. When the measurements are indexed, the change in size appears proportional to somatic growth. However, the argument is always whether this is growth or dilation. ${ }^{19}$ To us, this probably represents growth rather than dilation. Solymar and colleagues, ${ }^{11}$ in their study of 8 infants with critical aortic stenosis who underwent the Ross operation early in life, concluded that the pulmonary autograft in the aortic position does increase in size and that the pattern of this increase is suggestive of passive dilation in the early postoperative period, followed by normal active growth.

In conclusion, the Ross procedure for congenital aortic valve disease in children and young adults offers excellent hemodynamics, with the added advantage of real potential for growth. Reoperations on the reconstructed RVOT are infrequent and are much less demanding and life-threatening. The Ross procedure therefore should be considered the treatment of choice in this age group.

\section{References}

1. Sade RM, Crawford FA Jr, Fyle DA, Stroud MR. Valve prosthesis in children: a reassessment of anticoagulation. $J$ Thorac Cardiovasc Surg. 1988;95:533-61.

2. Chan WS, Anand S, Ginsberg J. Anticoagulation of pregnant women with mechanical heart valves. A systematic review of the literature. Arch Intern Med. 2000;160:191-6.

3. Salazar E, Izaguirre R, Verdejo J, Mutchinick O. Failure of adjusted doses of subcutaneous heparin to prevent thromboembolic phenomena in pregnant patients in the mechanical cardiac valve prostheses. $J$ Am Coll Cardiol. 1996;27:1698-703.

4. Wong V, Cheng $\mathrm{CH}$, Chan KC. Fetal and neonatal outcome of exposure to anticoagulants during pregnancy. Am J Med Genet. 1993;45: 17-21.

5. Kopf GS, Geha AS, Hellenbrand WE, Kleinman CS. Fate of left sided cardiac bioprosthesis valves in children. Arch Surg. 1986;121:488-90.

6. Clarke DR, Campbell DN, Hayward AR, Bishop DA. Degeneration of aortic valve allografts in young recipients. J Thorac Cardiovasc Surg. 1993;105:934-42.

7. Elkins RC, Knott-Craig CJ, Ward KE, Mcue C, Lane MM. Pulmonary autograft in children: realized growth potential. Ann Thorac Surg. 1994;57:1387-94

8. Ross D. Pulmonary valve autotransplantation (the Ross operation). $J$ Card Surg. 1988;3(suppl):313-9.

9. Duran C, Kumar N, Gometza B, Al-Halees Z. Indications and limitations of aortic valve reconstruction. Ann Thorac Surg. 1991;52:447-54.

10. Ross D, Jackson M, Davies J. The pulmonary autograft: a permanent aortic valve. Eur J Cardiothorac Surg. 1992;6:113-7.

11. Solymar L, Sudow G, Holmgren D. Increase in size of the pulmonary autograft after the Ross operation in children: Growth or dilation? $J$ Thorac Cardiovas Surg. 2000;119:4-9.

12. Matsuki O, Okita Y, Almeida RS, McGoldrick JP, Hooper TL, Robles A, et al. Two decades' experience with aortic valve replacement with pulmonary autograft. J Thorac Cardiovasc Surg. 1988;95:705-11.

13. Al-Halees Z, Kumar N, Gallo R, Gometza B, Duran C. Pulmonary autograft for aortic valve replacement in rheumatic disease: a caveat. Ann Thorac Surg. 1995;60:S172-6.

14. Pieters F, Al-Halees Z, Zwaan F, Hatle L. Autograft failure after the Ross operation in a rheumatic population: pre and postoperative echocardiographic observations. J Heart Valve Dis. 1996;5:404-9.
15. Jonas R. Radical aortic root enlargement in the infant and child. $J$ Card Surg. 1994;9(suppl):165-9.

16. Elkins RC, Knott-Craig CJ, McCue C, Love NM. Congenital aortic valve disease: Improved survival and quality of life. Ann Surg. 1997;225:503-10.

17. Smith JD, Ogino H, Hunt D, Laylor RM, Rose M, Yacoub MH. Humoral immune response to human aortic valve homografts. Ann Thorac Surg. 1995;60:S127-30.

18. Shaddy RE, Thompson DD, Osborne KA, Hawkins JA, Fuller TC. Persistence of human leukocyte antigen (HLA) antibodies after one year in children receiving cryopreserved valved allografts. Am J Cardiol. 1997;80:358-9.

19. Elkins RC. The Ross operation: applications to children. Semin Thorac Cardiovasc Surg. 1996;8:345-9.

\section{Discussion}

Dr Ronald C. Elkins (Oklahoma City, Okla). I would like to congratulate $\mathrm{Dr}$ Al-Halees and his group for an excellent clinical series of Ross operations in patients with congenital heart operations.

My first point is that I was struck by the differences in his patient population compared with that in most reported series. The male/female ratio was almost equal in this series, whereas in most of the series reported in the United States, a male/female ratio of at least 3:1 is reported. Could you suggest a reason for this?

The operative results were excellent, and the early postoperative echocardiographic results were likewise excellent, with no evidence of obstruction and only trivial autograft valve regurgitation. In this series of 49 patients with midterm follow-up (mean of 4 years), 16 patients now have mild and 3 have moderate autograft regurgitation. This is of some concern, especially with the length of follow-up.

Although you have demonstrated a mean value of the autograft anulus of $22 \mathrm{~mm}$ and a left ventricular outflow index that appears to have decreased over time, I would be more comfortable with your data on autograft growth if you had presented this information as the individual's $z$ values of the anulus on the basis of the body surface area rather than a mean value, which in the wide range of ages that you have probably does not reflect the true growth in some of these patients. Certainly, if you have a 22-mm anulus as your mean value, there are some patients who have an anulus significantly greater than one would anticipate for that body surface area. A 26-mm anulus means you have some patients with a body surface area of $2.6 \mathrm{~mm}^{2}$ for this to be normal. This would suggest that perhaps dilation has occurred in some patients. Did you have any patients who had a dilated aortic anulus at the time of the operation, and did you alter the management of these patients?

How did you select the size of your allograft valves? Although you have suggested a very low incidence of reoperation or RVOT complication, that certainly has not been our experience or the experience of other centers looking at these patients. In your data you report a $28 \%$ incidence of the allografts having some obstruction and $22 \%$ having moderate or severe pulmonary insufficiency. What do you think the real incidence of homograft valve dysfunction is going to be in this group of patients as they are followed up for 10 years?

I agree with your conclusions but believe that we have much to learn about this operation. There are many areas where continued study will allow us to change and alter our operative techniques, so that our patients may have better results. 
Dr Al-Halees. Thank you, Dr Elkins, for your remarks and questions. Your contributions for the Ross procedure have been very well known and outstanding.

In regard to the male/female ratio, I think there are some regional differences that could exist, and I believe this is probably because of that fact. For example, in our area, in general, LVOT obstructions are much rarer than the right-sided obstructions. Therefore, we see a lot of right-sided obstructions in our population, a higher incidence of tetralogy of Fallot, for example, than would be seen in the Western literature. I believe that there are some geographic and maybe racial differences between our population and the population in the West.

In terms of relating the growth to the body surface area in the way you suggested, I think this is what we will probably do in the group, particularly if we have a longer follow-up. What you have suggested is a more accurate measure of defining the growth versus dilatation. There was a publication from a group in Sweden that looked at 8 infants who underwent the Ross procedure at 2 weeks of age, and the suggestion from that article is that there is an initial dilatation followed by a real growth of the autograft.

In terms of the allograft, the mean size for our patients was 22 $\mathrm{mm}$, and we really do not have any specific formula to choose the size. We just go ahead and use the largest size possible for that patient. It also depends on the availability of the homograft in our storage. In general, homografts are not freely available for us as they are here, and we depend entirely on importing those from other sources. In the one patient who had the allograft explanted, a pericardial tube was reconstructed because, at the time, we did not have any homografts available.

Our incidence of reoperation for the allograft failure is lower because of our higher tolerance for pulmonary regurgitation and stenosis. As I mentioned, we noticed, in our group of patients, that the greatest hazard for development of the stenosis is really early on, maybe the first 1,2, or 3 years; afterward it seems that the process becomes much slower, and these patients can be managed well medically without reoperation.
Of course, for the whole group, a longer follow-up is required. We will keep monitoring them, and ideally in a few years we will have a longer follow-up. My own belief is that patients with rheumatic valve disease who have aortic stenosis as a manifestation of their aortic valve disease, or stenosis and regurgitation with the stenosis being the predominant lesion, will not have the same problems as patients with aortic regurgitation. I think that those patients with stenosis as the lesion will probably have stable function of the autograft. That is only a prediction. Only time can tell.

Dr Abdulla Ashmeg (Jeddah, Saudi Arabia). I have 2 questions for Dr Al-Halees.

First, sometimes we see a string sign on the right side, the homograft, that develops fairly early after the Ross operation. What is the cause of this severe diffuse stenosis of the homograft, and is it related?

My second question is related to one of your slides, where you showed that the progress of the obstruction of the right side slows down. I cannot understand that in a growing patient, such as in children. As they grow, the homograft is not going to grow. I expect stenosis to become more severe with time rather than to progress more slowly.

Dr Al-Halees. Thank you. I think some of those patients indeed have diffuse obstruction in the allograft that starts at the valve anulus and involves the valve leaflets, the pulmonary wall, and the distal anastomosis. Although there is no definite evidence in the literature, it is believed that there is some sort of an immune response that could be the reason behind this type of diffuse obstruction. Actually, when this happens, the balloon dilatation of this stenosis will not result in good relief of the obstruction.

Maybe for the same reason it can be used to explain why the process can slow down later on. I think when all the immune reaction is kind of dealt with in the first couple of years, then the process slows down, and there is no further deterioration in the obstruction. Of course, the condition of some patients will continue to deteriorate, with higher and higher gradients, but that is the smaller number of patients and not the whole group. 